\title{
ОБРАЗОВАТЕЛЬНАЯ КИНЕЗИОЛОГИЯ В ПРОФЕССИОНАЛЬНОЙ ДЕЯТЕЛЬНОСТИ ВРАЧА
}

\section{EDUCATIONAL KINESIOLOGY IN THE PROFESSIONAL ACTIVITY OF A DOCTOR \\ N. Chistiakova \\ A. Korobko}

Summary: Educational kinesiology is a holistic psychological and pedagogical direction at the intersection of neuropsychology, psychophysiology and pedagogy. As a health-preserving technology in the doctor's practice, it is aimed at a healthy lifestyle promoting and health self-preservation skills teaching. The problematic field of educational kinesiology includes the prenosological direction in the practice of active use of preventive-corrective methods of the organism's functional recovery.

Keywords: doctors' psychological and pedagogical activity, educational kinesiology, stable pathological state, operated movements.
Чистякова Наталья Викторовна

К.псх.н., ассистент, ФГАОУ ВО «РНИМУ им. Н.И. Пирогова» Минздрава России

chistiakova_nv@rsmu.ru

Коробко Андрей Иванович

К.воен.н., ФГАОУ ВО «РНИМУ Им. Н.И. Пирогова»

Минздрава России

korobko_ai@rsmu.ru

Аннотация: Образовательная кинезиология представляет собой холистическое психолого-педагогическое направление на стыке нейропсихологии, психофизиологии и педагогики. Как здоровьесберегающая технология в практической деятельности врача, она направлена на пропаганду здорового образа жизни и обучение навыкам самосохранения здоровья. Проблемное поле образовательной кинезиологии включает донозологическое направление в практике активного применения превентивно-коррекционных методов функционального восстановления организма.

Ключевые слова: психолого-педагогическая деятельность врача, образовательная кинезиология, устойчивое патологическое состояние, произвольные движения.

Образовательная кинезиология в практической деятельности врача с активным применением миофасциальных техник, комплекса дыхательных упражнений, рефлексотерапии обеспечивает проприорецептивный контроль наружного контура тела и способствует развитию внутреннего ресурсного потенциала у пациента, выполняя защитную функцию с целью сохранения целостности организма.

Рассматривая этапы прогредиентного течения заболевания в анализе функциональных изменений организма, подход гомотоксикологии Г. Реккевега позволяет оценить степень влияния воздействия внешних и внужений педагогики, психологии и медицины.

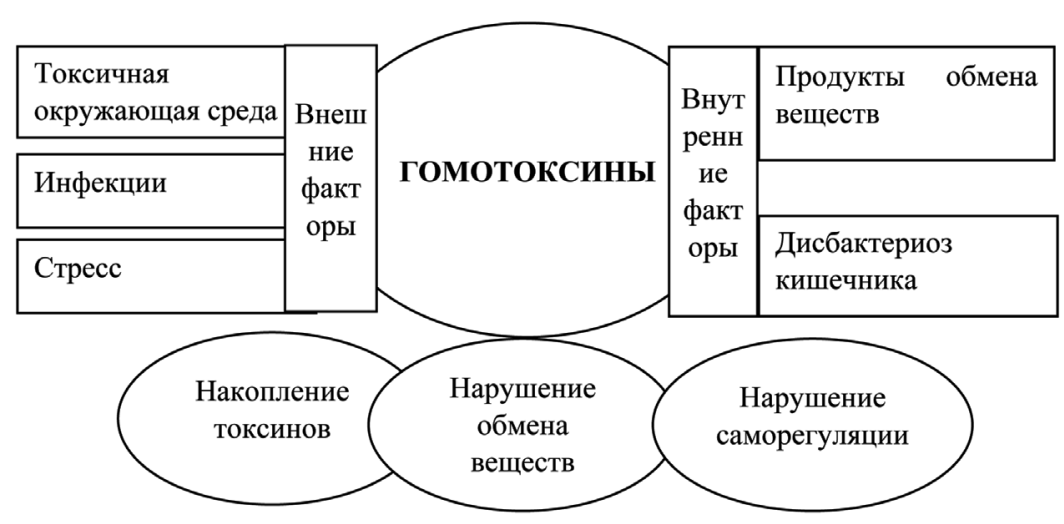

Рис. 1. Образовательная кинезиология как здоровьесберегающая технология в практической деятельности врача 
тренних факторов на состояние как физического, так и психического здоровья (см. рис. 1) [8].

При превышении порогового значения в системе проприоцептивной чувствительности в ходе терапевтического воздействия запускаются адаптационные механизмы внутреннего реагирования, что согласуется с общепризнанными остеопатическими теориями (A. T. Still, R. B. Fuller). В качестве примера можно привести стрессовый (или усталостный) перелом, причиной которого служит мышечное ослабление, связанное с выпадением соответствующих движений на фоне чрезмерно резкого повышения тонуса мышц.

Теория устойчивого патологического состояния (УПС) Н.П. Бехтеревой как наиболее общего механизма развития болезни демонстрирует эффективность применения немедикаментозных методов лечения, в особенности при лекарственной резистентности [1]. Указанная группа методов предлагает активное применение факторов, аналогичных адаптационным защитным механизмам по характеру воздействия на функциональное состояние организма. Основная цель немедикаментозной терапии - переход от патологического к устойчивому нормальному состоянию (УНС). УНС обеспечивается сбалансированным взаимодействием центральной и периферической нервной системы. Одним из инновационных направлений немедикаментозной терапии является прикладная кинезиология [5].

Образовательная кинезиология, сформированная на основе прикладного направления, представляет собой холистическое психолого-педагогическое направление на стыке нейропсихологии, психофизиологии и педагогики [6]. «Гимнастика мозга», предложенная П. Деннисоном [3], как основа образовательной кинезиологии направлена на формирование переключения внимания, гибкости мышления, пластичности поведения и снижение тревожности в парадигме «мышление - эмоции тело», условно называемой «триадой здоровья».

Исходя из здравоцентрической парадигмы, проблемное поле образовательной кинезиологии в профессиональной деятельности врача включает донозологическое направление в практике превентивно-коррекционных методов функционального восстановления организма за счет актуализации биопсихосоциальных ресурсов личности через развитие проприорецептивной чувствительности, рефлекторной регуляции движений и мышечного тонуса (см. рис. 2).

Н.А. Бернштейн подробно описал систему уровневой организации произвольных движений, а также их связи с высшими корковыми отделами мозга. Произвольные движения как сложные многоуровневые системы основываются на кинестетической афферентации, которая является важнейшим фактором регуляции поведения субъекта. В своей концепции функциональных систем П.К. Анохин выделяет предпусковую, текущую и обратную формы афферентации в анализе структуры поведенческого акта. А.Р. Лурия включил в корковое звено двигательного анализатора сенсорные, моторные и ассоциативные поля [7]. У. Пенфилд и Г. Джаспер указывали на их особое функциональное значение. Согласно современным представлениям в физиологии и нейропсихологии, произвольные движения представляют собой сложные афферентированные системы, которые реализуются благодаря интегративной деятельности центральной нервной системы.

В базовой программе образовательной кинезиологии «балансы действий» как специальные двигательные упражнения способствуют общему функциональному восстановлению организма, развитию самоорганизации

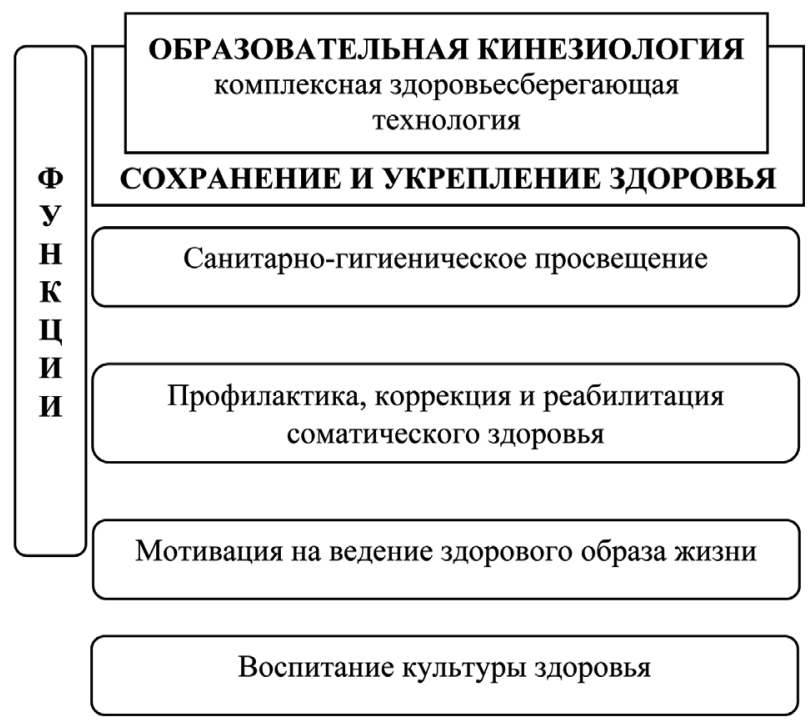

Рис. 2. Образовательная кинезиология как здоровьесберегающая технология в практической деятельности врача 
и саморегуляции с целью сохранения внутриличностного равновесия. Активное применение образовательной кинезиологии как здоровьесберегающей технологии в современной превентологии способствует укреплению здоровья, благодаря повышению координации в деятельности жизненно важных систем организма.

\section{ЛИТЕРАТУРА}

1. Бехтерева, Н.П. Магия мозга и лабиринты жизни / Н.П. Бехтерева. - Москва: АСТ, сор., 2019. - 383 с.

2. Васильева, Е.Ю. Педагогика в клинической практике врача: учебное пособие / Е.Ю. Васильева, М.Ю. Гайкина, Т.В. Тагаева ; Министерство здравоохранения Российской Федерации, Федеральное государственное бюджетное образовательное учреждение высшего образования «Северный государственный медицинский университет» Министерства здравоохранения Российской Федерации. Архангельск: Изд-во Северного гос. мед. ун-та, 2017. - 117 с.

3. Деннисон, Пол Е. Гимнастика мозга : книга для учителей и родителей : дополнение к «Гимнастике мозга» : простые упражнения для активизации обоих полушарий / Пол Е. Деннисон, Гейл Е. Деннисон. Санкт-Петербург: Весь, 2015. - 307 с.

4. Морозов, М.А. Здоровый человек и его окружение. Здоровьесберегающие технологии : учебное пособие / М.А. Морозов. Санкт-Петербург [и др.]: Лань, 2016. $-371 \mathrm{C}$.

5. Разумов, А.Н., Бобровницкий, И.П., Шакула, А.В. Служба восстановительной медицины и ее роль в охране здоровья населения / А.Н. Разумов, И.П. Бобровницкий, А.В. Шакула / Вестник восстановительной медицины. 2003. № 4. С. 3-5.

6. Синицина, И.А. Основы образовательной кинезиологии : учебно-методическое пособие / И.А. Синицина, Р.М. Салимова ; Министерство образования и науки Российской Федерации, Стерлитамакский филиал Федерального государственного бюджетного образовательного учреждения высшего образования «Башкирский государственный университет». Стерлитамак: Стерлитамакский филиал БашГУ, 2016. - 127 с.

7. Хомская, Е.Д. Нейропсихология: учебник для студентов, обучающихся по направлению «Психология» и специальностям «Психология» и «Клиническая психология» / Е.Д. Хомская ; Московский гос. ун-т им. М.В. Ломоносова. 4-е изд. Москва [и др.] : Питер, 2014. - 496 с.

8. Ernst, E., Schmidt, K. Homotoxicology - a review of randomised clinical trials / E. Ernst, K. Schmidt // Eur. J. Clin. Pharmacol. 2004 Jul.; 60(5): $299-306$. doi: 10.1007/s00228-004-0776-6. Epub 2004 Jun 9. PMID: 15197516.

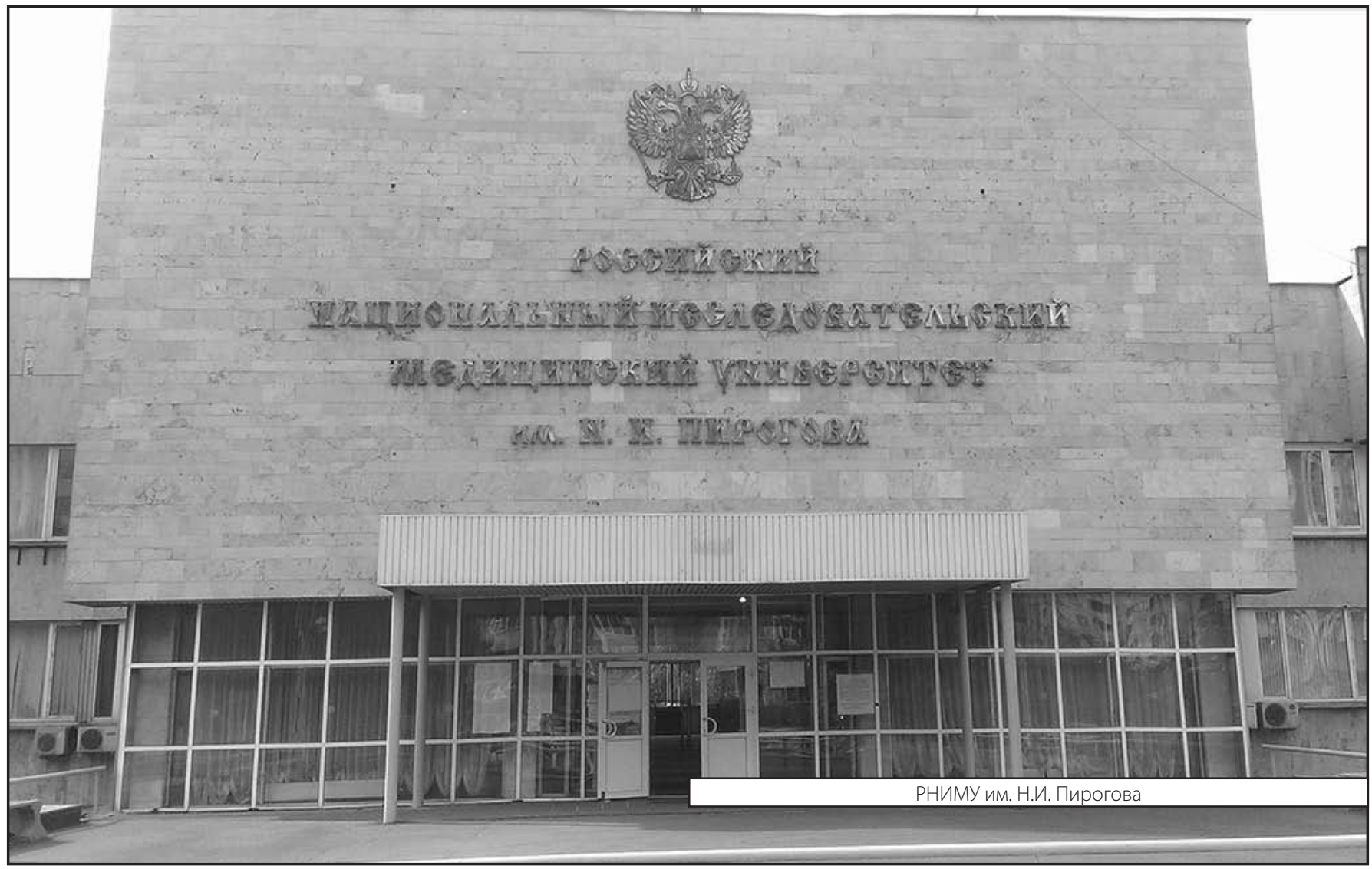

